\title{
Risk Analysis of Transmission Line Patrol Based on DEMATEL Method
}

\author{
Meiyu Li ${ }^{1}$, Zhengyun Fang ${ }^{2}$, Shilin $\mathrm{Li}^{1}$, Ailin Zhao ${ }^{3 *}$, Ming Zeng ${ }^{3}$, Yongli Wang ${ }^{3}$ \\ ${ }^{1}$ Electric Power Research Institute of Yunnan Power Grid Co., Ltd, Kunming, Yunnan, China \\ ${ }^{2}$ School of Land and Resources Engineering, Kunming University of Science and Technology, Kunming, \\ Yunnan, China \\ ${ }^{3}$ School of Economics and Management, North China Electric Power University, Beijing, China \\ *Corresponding Author.
}

\begin{abstract}
As the scale of power network construction increases, transmission lines that undertake transmission tasks are facing greater challenges in patrol and maintenance work. Therefore, analyzing the factors that affect transmission line patrol and maintenance has become an urgent problem in the power industry. This paper analyzes the influencing factors from the four dimensions of natural risk, transmission operation risk, transmission line risk, and other man-made risks, and uses the DEMATEL analysis method to identify the relationship between different factors, and obtains the key influencing factors, and then proposes Corresponding strategies to deal with the risk of transmission line patrol, hope to have a certain reference effect on the patrol work, so as to ensure the stability of transmission lines.
\end{abstract}

Keywords: Transmission line, patrol risk, DEMATEL analysis method

\section{Introduction}

With the increase of the scale of China's power network construction, the problems in the transmission line inspection work are increasing day by day, and failures will bring serious impact to the society. Therefore, it is extremely necessary to do a good job of transmission line patrol. In recent years, many literatures have studied the risk of patrol work. Literature [1] [2] summarized the risk factors of patrol of transmission lines in a certain place and puts forward corresponding solutions for many problems in the patrol of transmission lines. Literature [3] thought that improving the patrol level of transmission lines can ensure the safe operation of transmission lines and puts forward countermeasures for various risks affecting transmission lines. Although the existing literatures have classified and sorted out the patrol risks of transmission lines, and put forward countermeasures, they did not consider the correlation between risks as a whole, and did not establish an index system to evaluate the risk problems. At present, methods such as decision-making laboratory analysis and interpretative structural model can explain the relationship between factors in complex systems. Literature [4] used DEMATEL model to study the influence factors of the implementation of VAT reform policy on the development of construction enterprises. Literature [5] analyzed the influencing factors of the integration development of industry and city in the new city by using the decision-making laboratory analysis method. Literature [6] used DEMATEL model to explain the factors restricting the development of prefabricated buildings.

To sum up, this paper will summarize the risk factors that affect the patrol work of transmission lines, and use quantitative analysis with decision-making laboratory analysis method (DEMATEL) to get the key elements, cause elements and result elements that affect the patrol work, and then put forward the strategies to deal with the risk.

\section{Risk Analysis of Transmission Line Patrol}

2.1 Impact of natural risk

ISSN: 0010-8189

(C) CONVERTER 2020

www.converter-magazine.info 
Transmission lines are often affected by natural factors, which are unpredictable and highly dangerous. The main manifestations are as follows: Transmission lines exposed in the natural environment will be eroded. Due to natural disasters such as wind, lightning, landslide and debris flow, transmission lines will be damaged to varying degrees [7]. Transmission lines are located in steep terrain and have a wide span, difficult to observe and patrol. Trees are planted in many places along the path, which will directly affect the stability of the transmission line.

\subsection{Impact of transmission operation risk}

Transmission operation is an important part of the transmission line operation. Therefore, the transmission line operation factors will have certain risks to the patrol work. The main influencing factors are as follows: first of all, if the operators do not carry out the on-site investigation carefully due to the lack of safety and responsibility awareness, the follow-up patrol work will be affected. Moreover, if the operation mode of power transmission equipment is not reasonable, there will also be certain risks when completing the construction work. Finally, there will be hidden trouble in the construction of transmission line. If the construction personnel do not install the transmission line according to the standard process, the normal operation of the transmission line will be affected by the low quality of line installation.

\subsection{Impact of transmission line risk}

With the increase of power consumption and service life of transmission lines, the faster the rate of damage and aging, the higher the frequency of occurrence. Moreover, if the transmission line clamp is not firm or the sag is low, the safety distance is not enough, which will also affect the normal operation of the transmission lines [8]. And if the new transmission equipment is used, the non-standard operation of technical personnel will lead to some potential safety hazards in the construction of transmission lines.

\subsection{Impact of other human risks}

The influence of other human factors on transmission lines is shown in all aspects. For example, the impact of traffic accidents on transmission lines. In a car accident, some vehicles will hit the pole and cause them to tilt, thus causing damage to the transmission lines [9]. The impact of illegal operation on transmission lines. In the construction process of factories and residential buildings, if the construction is not carried out in accordance with the specifications, it will lead to disorderly transmission lines and small vertical distance between the lines and the ground. Due to the low safety awareness of transmission line operation, some lawless elements seek private interests by stealing power equipment and lines, which will also affect the smooth operation of transmission lines. All of these human factors will have a certain impact on the normal patrol of transmission lines. The specific risk factors affecting the patrol of transmission lines are shown in Table 1.

Table 1 Risk factors for patrol of transmission lines

\begin{tabular}{|c|c|}
\hline First level indicators & Secondary indicators \\
\hline \multirow{2}{*}{ Natural risk $\left(x_{1}-x_{4}\right)$} & Risk of transmission line erosion and aging $x_{1}$ \\
\cline { 2 - 2 } & Natural disaster risk $x_{2}$ \\
\cline { 2 - 2 } & Terrain risk of transmission line $x_{3}$ \\
\cline { 2 - 2 } & Risk of vegetation cluster $x_{4}$ \\
\hline \multirow{2}{*}{$\begin{array}{c}\text { Transmission operation risk } \\
\left(x_{5}-x_{7}\right)\end{array}$} & Investigation risk $x_{5}$ \\
\cline { 2 - 2 } & Equipment operation risk $x_{6}$ \\
\cline { 2 - 2 } Transmission lines risk $\left(x_{8}-x_{9}\right)$ & Construction failure risk $x_{7}$ \\
\cline { 2 - 2 } & Transmission line fault risk $x_{8}$ \\
\hline \multirow{2}{*}{\begin{tabular}{c} 
Other human risks $\left(x_{10}-x_{12}\right)$ \\
\cline { 2 - 2 }
\end{tabular}} & Transmission line operation risk $x_{9}$ \\
\cline { 2 - 2 } & Traffic breakdown risk $x_{10}$ \\
\hline
\end{tabular}

ISSN: 0010-8189

(C) CONVERTER 2020 


\section{DEMATEL Model Analysis of Risk Factors}

\subsection{Basic principle}

The DEMATEL method (decision making trial \& Evaluation Laboratory) [10] is an intuitive method that Bastille Laboratory of the United States used graph theory and matrix tools to solve complex problems in 1971. This method uses the form of matrix to express the identified factors, and finds out the influence of each factor in the system on other factors by calculating the centrality and cause degree, and then selects the main factors in the system.

This method is mainly used in the system of uncertain relationship between elements, according to the experience and knowledge of experts in dealing with problems, using mathematical methods such as matrix and graphics to get the degree of correlation between various factors in the system, and then find out the most important index in the complex system. Through the analysis, transmission lines patrol problem is affected by many interactive factors, so this method is more suitable for analysis.

\subsection{Implementation steps}

Step 1: Determine the influencing factors in the analysis system: set as $x_{1}, x_{2}, x_{3}, \cdots, x_{n}$.

Step 2: Establish a direct influence matrix to reflect the degree of correlation between various factors. The influencing factors of transmission line patrol are recorded as $Y_{i}(i=1,2,3, \cdots, n)$, and the correlation degree between the factors is recorded as $y_{i j}$. At that time $i=j$, because their own factors will not have mutual influence on themselves, so $y_{i j}=0$. Through the use of expert experience and knowledge, interviews with participants, questionnaires and other methods to obtain the degree of correlation between any two factors, the direct impact matrix $Y$ is established after the statistics of the experimental results:

$$
Y=\left\{\begin{array}{cccc}
0 & y_{12} & \cdots & y_{1 n} \\
y_{21} & 0 & \cdots & y_{2 n} \\
\vdots & \vdots & \ddots & \vdots \\
y_{n 1} & y_{n 2} & \cdots & 0
\end{array}\right\}
$$

$Y=\left[y_{i j}\right]_{n \times n}=0,1,2,3,4$, respectively represent the degree of direct influence of factor $i$ on factor $j$, and the numerical values respectively represent no influence, weaker influence, weak influence, strong influence and stronger influence.

Step 3: The calculation standardization directly affects the matrix $Z$. The standardized influence matrix $Z$ is obtained by calculating the maximum value of the sum of factors in each row of matrix $Y$. The calculation formula is as follows:

$$
Z=Y / \max \sum_{j=1}^{j=n} y_{i j}=\left[z_{i j}\right]_{n \times n},\left(0 \leq z_{i j} \leq 1\right)
$$

Step 4: Determine the comprehensive influence matrix $T$. By adding the standardized influence matrix $Z$, the

ISSN: 0010-8189 
calculation formula is as follows:

$$
T=Z+Z^{2}+Z^{3}+\cdots+Z^{n}=\left(t_{i j}\right)_{n \times n}^{2}
$$

When $n$ tends to infinity, it can be approximately calculated by formula $T=Z \frac{I}{I-Z}$, and $I$ represents the identity matrix.

Step 5: According to the influence elements in $T$, calculate the influence degree $B$, affected degree $\bar{B}$, center degree $C$ and cause degree $E$ of each risk factor. The influence degree $T$ is the sum of row vectors in. The affected degree is the sum of column vectors. The centrality of $T_{i}$ is the sum of row vector and column vector, namely $C=B+\bar{B}$; The centrality indicates the effect of this factor in the system. The larger the value is, the greater the effect is. The reason degree is the difference between row vector and column vector, that is, $E=B-\bar{B}$. If $E<0$, the risk factor is the result factor, otherwise, it is the cause factor.

Step 6: The results are visualized, and the relationship between the factors is analyzed to find out the key factors in the system.

\section{Example Analysis of Transmission Line Patrol Based on DEMATE}

\subsection{DEMATEL calculation process}

Step 1: Establish direct impact matrix $Y$.

In this experiment, a total of 30 questionnaires are sent out to the high-voltage transmission line patrol personnel and department management personnel of a power supply bureau, excluding the highly repetitive invalid questionnaires, a total of 24 valid questionnaires are recovered. So the recovery rate of this questionnaire survey is $80 \%$. Taking the impact of natural disasters on the operation risk of transmission lines as an example. It can be seen from the feedback data of the questionnaire that, $4 \%$ of the respondents think that the impact of natural disasters on the operation risk of transmission lines is almost negligible, $6 \%$ of the respondents think that the impact is weak, $12 \%$ of the respondents think that the impact is general, $30 \%$ of the respondents hold the view of high degree of influence, and $48 \%$ who is accounting for the highest proportion hold the view of high degree of influence.. According to the questionnaire results, the risk factors influencing the dimension inspection are scored. The mean value of each data in 24 questionnaires is calculated, and the direct influence matrix $Y$ is obtained according to formula (4), as shown in Table 2.

$$
y_{i j}= \begin{cases}0 & 0 \leq \bar{X}_{i j}<0.5 \\ 1 & 0.5 \leq \bar{X}_{i j}<1.5 \\ 2 & 1.5 \leq \bar{X}_{i j}<2.5 \\ 3 & 2.5 \leq \bar{X}_{i j}<3.5 \\ 4 & 3.5 \leq \bar{X}_{i j}<4\end{cases}
$$

Table 2 Direct influence matrix of risk factors of transmission line inspection

\begin{tabular}{|c|c|c|c|c|c|c|c|c|c|c|c|c|}
\hline Risks & $x_{1}$ & $x_{2}$ & $x_{3}$ & $x_{4}$ & $x_{5}$ & $x_{6}$ & $x_{7}$ & $x_{8}$ & $x_{9}$ & $x_{10}$ & $x_{11}$ & $x_{12}$ \\
\hline$x_{1}$ & 0 & 0 & 0 & 0 & 2 & 3 & 1 & 4 & 4 & 0 & 0 & 0 \\
\hline$x_{2}$ & 4 & 0 & 2 & 3 & 4 & 3 & 2 & 3 & 3 & 3 & 2 & 1 \\
\hline
\end{tabular}

ISSN: 0010-8189 
CONVERTER MAGAZINE

Volume 2021, No. 4

\begin{tabular}{|l|l|l|l|l|l|l|l|l|l|l|l|l|l|}
\hline$x_{3}$ & 3 & 2 & 0 & 2 & 3 & 2 & 1 & 1 & 3 & 4 & 2 & 2 \\
\hline$x_{4}$ & 1 & 0 & 0 & 0 & 2 & 3 & 2 & 4 & 3 & 1 & 1 & 2 \\
\hline$x_{5}$ & 0 & 0 & 0 & 0 & 0 & 3 & 4 & 2 & 4 & 0 & 0 & 0 \\
\hline$x_{6}$ & 0 & 0 & 0 & 0 & 3 & 0 & 4 & 3 & 4 & 0 & 0 & 0 \\
\hline$x_{7}$ & 0 & 0 & 0 & 0 & 2 & 4 & 0 & 3 & 4 & 0 & 1 & 0 \\
\hline$x_{8}$ & 1 & 0 & 0 & 0 & 2 & 4 & 3 & 0 & 4 & 0 & 0 & 0 \\
\hline$x_{9}$ & 0 & 0 & 0 & 0 & 3 & 4 & 2 & 3 & 0 & 0 & 0 & 0 \\
\hline$x_{10}$ & 0 & 0 & 0 & 0 & 1 & 0 & 2 & 3 & 2 & 0 & 2 & 1 \\
\hline$x_{11}$ & 3 & 0 & 0 & 0 & 3 & 1 & 2 & 3 & 4 & 1 & 0 & 0 \\
\hline$x_{12}$ & 0 & 0 & 0 & 0 & 0 & 2 & 1 & 4 & 3 & 4 & 2 & 0 \\
\hline
\end{tabular}

Step 2: Determine the comprehensive impact matrix $T$.

First, the standardized matrix $Z$ can be obtained by formula (2), and then the comprehensive influence matrix $T$ can be obtained by formula (3), as shown in Table 3.

Table 3 Comprehensive influence matrix $\mathrm{T}$ of risk factors of transmission line inspection

\begin{tabular}{|c|c|c|c|c|c|c|c|c|c|c|c|c|}
\hline Risks & $x_{1}$ & $x_{2}$ & $x_{3}$ & $x_{4}$ & $x_{5}$ & $x_{6}$ & $x_{7}$ & $x_{8}$ & $x_{9}$ & $x_{10}$ & $x_{11}$ & $x_{12}$ \\
\hline$x_{1}$ & 0.007 & 0 & 0 & 0 & 0.128 & 0.183 & 0.109 & 0.194 & 0.217 & 0 & 0.004 & 0 \\
\hline$x_{2}$ & 0.162 & 0.004 & 0.067 & 0.105 & 0.260 & 0.267 & 0.214 & 0.262 & 0.299 & 0.123 & 0.093 & 0.049 \\
\hline$x_{3}$ & 0.127 & 0.067 & 0.004 & 0.074 & 0.206 & 0.202 & 0.156 & 0.178 & 0.262 & 0.157 & 0.095 & 0.079 \\
\hline$x_{4}$ & 0.045 & 0 & 0 & 0 & 0.144 & 0.206 & 0.160 & 0.226 & 0.220 & 0.044 & 0.046 & 0.068 \\
\hline$x_{5}$ & 0.005 & 0 & 0 & 0 & 0.061 & 0.178 & 0.193 & 0.130 & 0.210 & 0 & 0.006 & 0 \\
\hline$x_{6}$ & 0.006 & 0 & 0 & 0 & 0.156 & 0.093 & 0.198 & 0.163 & 0.216 & 0 & 0.007 & 0 \\
\hline$x_{7}$ & 0.009 & 0 & 0 & 0 & 0.130 & 0.210 & 0.079 & 0.164 & 0.217 & 0.001 & 0.036 & 0 \\
\hline$x_{8}$ & 0.036 & 0 & 0 & 0 & 0.129 & 0.211 & 0.169 & 0.074 & 0.217 & 0 & 0.006 & 0 \\
\hline$x_{9}$ & 0.006 & 0 & 0 & 0 & 0.148 & 0.199 & 0.134 & 0.153 & 0.086 & 0 & 0.004 & 0 \\
\hline$x_{10}$ & 0.012 & 0 & 0 & 0 & 0.080 & 0.068 & 0.118 & 0.152 & 0.138 & 0.007 & 0.073 & 0.034 \\
\hline$x_{11}$ & 0.107 & 0 & 0 & 0 & 0.168 & 0.136 & 0.147 & 0.182 & 0.235 & 0.034 & 0.007 & 0.001 \\
\hline$x_{12}$ & 0.015 & 0 & 0 & 0 & 0.069 & 0.146 & 0.111 & 0.207 & 0.193 & 0.137 & 0.080 & 0.005 \\
\hline
\end{tabular}

Step 3: Calculate influence degree $B$, affected degree $\bar{B}$, center degree $C$ and cause degree $E$.

According to the calculation, the analysis results of risk factors are shown in Table 4.

Table 4 Comprehensive influence degree of risk factors for patrol of transmission line

\begin{tabular}{|c|c|c|c|c|}
\hline Risks & Influence degree $B$ & Affected degree $\bar{B}$ & Center degree $C$ & Cause degree $E$ \\
\hline$x_{1}$ & 0.841 & 0.538 & 1.378 & 0.303 \\
\hline$x_{2}$ & 0.846 & 1.788 & 2.635 & -0.942 \\
\hline$x_{3}$ & 1.608 & 0.071 & 1.680 & 1.537 \\
\hline$x_{4}$ & 1.160 & 0.179 & 1.338 & 0.981 \\
\hline$x_{5}$ & 0.784 & 1.679 & 2.463 & -0.896 \\
\hline
\end{tabular}

ISSN: 0010-8189 


\begin{tabular}{|l|l|l|l|l|}
\hline$x_{6}$ & 0.839 & 2.100 & 2.939 & -1.260 \\
\hline$x_{7}$ & 1.905 & 0.071 & 1.977 & 1.834 \\
\hline$x_{8}$ & 0.841 & 2.084 & 2.925 & -1.243 \\
\hline$x_{9}$ & 0.731 & 2.509 & 3.239 & -1.778 \\
\hline$x_{10}$ & 0.682 & 0.503 & 1.185 & 0.179 \\
\hline$x_{11}$ & 1.018 & 0.458 & 1.475 & 0.560 \\
\hline$x_{12}$ & 0.961 & 0.236 & 1.197 & 0.726 \\
\hline
\end{tabular}

Step 4: Result visualization.

In this paper, the calculation results of risk factors are obtained through the calculation of MATLAB. In order to intuitively analyze the key influencing factors in the patrol work, the results are expressed in the form of pictures. As shown in Figure 1:

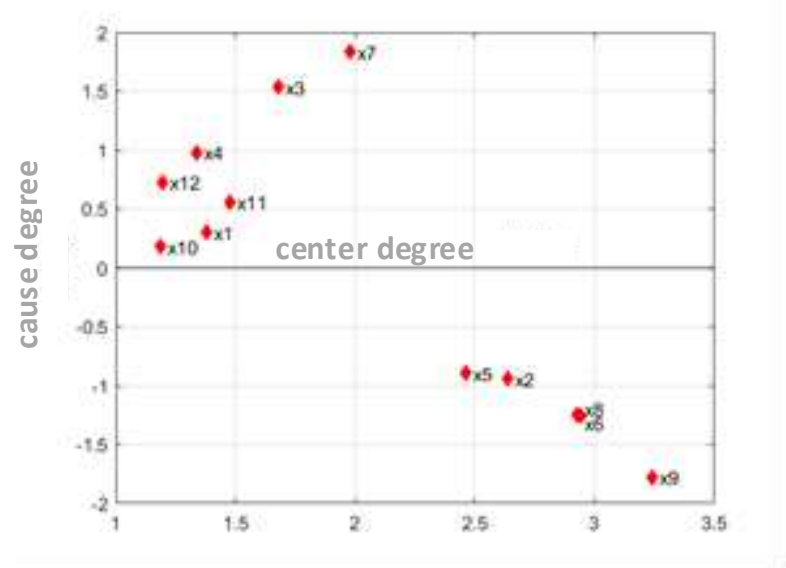

Fig 1: Cause-result analysis chart

\subsection{Analysis of calculation examples}

\subsubsection{Data analysis}

As shown in table 4 and figure $1, x_{9}, x_{6}, x_{8}, x_{2}$, are the top four factors of centrality, indicating that these four indicators play a greater role in the patrol system. From the perspective of causal degree, the top four factors with positive causal degree are $x_{7}, x_{3}, x_{4}, x_{12}$, which indicates that if these risks occur, there is a great probability that other risks will occur. There are $x_{8}, x_{2}, x_{5}, x_{6}$ and $x_{9}$ with negative cause degree, which indicates that these risks are easily affected by other risks.

\subsubsection{Centrality analysis}

Centrality refers to the effect of the factor on the patrol work. The larger the value is, the more important the risk factor plays in the system. The order from large to small is $x_{9}, x_{6}, x_{8}, x_{2}, x_{5}, x_{7}, x_{3}, x_{11}, x_{1}, x_{4}, x_{12}, x_{10}$. In terms of specific analysis, $x_{9}$ and $x_{6}$ are the top two risk factors that have a key impact on the patrol work, $x_{12}$ and $x_{10}$ is in the last two places. It indicates that the patrol work is less affected by it.

\subsubsection{Cause analysis}

The top four key risk indicators affecting the patrol work are the transmission line operation risk, equipment

ISSN: 0010-8189 
operation risk, transmission line fault risk and natural disaster risk. Among them, the two most critical indicators are transmission line fault risk and equipment operation risk, which indicates that these two risk factors have an impact on other risk indicators. Those with positive causal degree are called causal factors, including $x_{7}, x_{3}, x_{4}$, $x_{12}, x_{11}, x_{1}, x_{10}$. These risk factors have a significant impact on other risk factors. Among them, the construction failure risk and terrain risk are the most important factors affecting the patrol work, which indicates that the use of relevant tools and terrain problems should be considered. Negative cause degree is called result factor. Result factor is easily affected by external factors. Equipment operation risk and line operation risk are obviously affected by other factors.

\section{Risk Strategy of Transmission Line Patrol}

Based on the above risk analysis of patrol work, it can see that transmission line fault risk, transmission line operation risk, equipment operation risk and natural disaster risk are the key factors affecting patrol work. Therefore, this paper puts forward the following risk response strategies around these four key risk indicators.

For the transmission line fault risk, on the one hand, before the line equipment is put into operation, the relevant inspection personnel should conduct a comprehensive evaluation on these products. It is convenient to judge whether the transmission line is suitable for installation and operation according to the evaluation results, and carry out regular patrol to prevent faults and accidents. On the other hand, to accurately evaluate the operation state of transmission lines, the state evaluation should fully describe the deterioration state quantity and its corresponding towers, the safe distance of line conductors to trees, houses and other places that do not meet the operation requirements or affect the safe operation of hidden dangers, so as to ensure that the evaluation results reflect the health state of line operation accurately, truly and completely.

In view of the operation risk of transmission lines, on the one hand, we should pay attention to the systematic management of basic patrol data, and use cloud computing, big data and other information technology to mine the potential value of patrol data, so as to provide a theoretical basis for the effective preparation of patrol plan. On the other hand, it is necessary to carry out category refinement and differentiated management for various types of transmission line operation, and select appropriate patrol methods, such as daily patrol, special patrol, night patrol, supervisory patrol, professional patrol, fault patrol, etc.

For equipment operation risk, first of all, the patrol personnel need to carry out professional training before they formally enter the work, make clear the patrol process, and be familiar with the operation guidance. Secondly, the company should regularly train and assess the patrolmen in the company system, technical standards and other aspects. Finally, the maintenance of the equipment should be recorded correctly, supervised from the four dimensions of equipment account, defect, test, maintenance and overhaul. The basic information of the responsible equipment account should be updated in real time, so as to avoid the risk of equipment in the operation process.

For the risk of natural disasters, on the one hand, it should be classified according to the meteorological and geological conditions of different areas, and corresponding preventive measures should be taken according to them, so as to ensure the smooth development of patrol work and reduce the serious impact caused by the natural environment. For example, for natural disasters such as lightning strike, lightning rod, arrester and other equipment should be installed in advance according to local conditions [11], and regular implementation and management of maintenance work should be strengthened. In view of the lightning active section, the operation and maintenance cycle should be reasonably shortened to ensure that there will not be lightning events, which will affect the smooth operation of the transmission line. On the other hand, it is necessary to deal with the hidden danger regularly. For example, for the general hidden danger such as the tree barrier that cannot be eliminated within the specified time, it must be monitored for a long time and regularly, and the situation of the tree barrier hidden danger must be reported in time. For the tree barrier hidden danger that cannot be dealt with for a long time, it is necessary to ask the superior department for coordination.

ISSN: 0010-8189

(c) CONVERTER 2020

www.converter-magazine.info 


\section{Conclusion}

In this paper, a risk analysis method of transmission line patrol based on DEMATEL is proposed:

(1) Firstly, this paper analyzes the risks that may be encountered in the patrol work, and summarizes four types of risks, which are natural risk, transmission operation risk, transmission line risk and other man-made risks. In view of these four types of risks, this paper further refines 12 sub categories of risks, which are transmission line erosion, aging risk, natural disaster risk, terrain risk, vegetation risk, survey risk, equipment operation risk, construction failure risk, transmission line failure risk, transmission line operation risk, traffic failure risk, high-altitude debris risk, illegal risk. So as to prepare for the following analysis using DEMATEL model.

(2) Secondly, the principle of DEMATEL method is introduced. According to the actual situation of a power supply bureau, the example analysis shows that the fault risk and operation risk are in the core position of the system, which has a certain impact on other risk indicators. In the patrol work, the most common risk factors are equipment operation risk and natural disaster risk. Natural disaster and terrain risk are the most influential factors, and the most vulnerable factors are equipment operation risk and transmission line operation risk.

(3) Finally, according to the results of the above analysis, the four key risk indicators which are line operation risk, equipment operation risk and natural disaster risk put forward corresponding countermeasures.

\section{Acknowledgements}

This research was supported by Research on Technical Economy and Policy Mechanism of Transmission Line Market Patrol. (Southern Power Grid Corporation Technology Project, YNKJXM20190729).

\section{References}

[1] W.H. Yao. "Patrol risks and solutions of transmission lines in Tibet. Low Carbon World," vol. 32, pp. 61-62, 2017.

[2] P. Wang. "Analysis of transmission line patrol risks and countermeasures," Shandong Industrial Technology, vol. 23, pp. 1591, 2017.

[3] S. Huang. "Analysis of transmission line patrol risks and solutions," Journal of Science and Technology Economy, vol. 26, no. 27, pp. 72, 2018.

[4] C. Liu, W. You. "Analysis of influence switching business tax to VAT on the development of construction enterprise based on DEMATEL method," Journal of Engineering Management, vol. 30, no. 5, pp. 6-11, 2016.

[5] J.M. Yang, W. Wang, X.X. Gong. "Key Factors for development of new town's production-city integration based on DEMATEL," Journal of Engineering Management, vol. 31, no. 6, pp. 45-49, 2017, 2017.

[6] Y. Zhu, G. Xue. "Study on factors influencing the cost of prefabricated buildings based on DEMATEL," Value Engineering, vol. 38, no. 15, pp. 5-7, 2019.

[7] Z.B. Wu. "Research on influencing factors of prefabricated building cost based on DEMATEL," China New Technology and New Products, vol. 4, pp. 67-68, 2014.

[8] F.X. Peng. "Research on risk assessment method for automatic operation and maintenance of high voltage transmission lines," Automation and Instrumentation, vol. 1, pp. 64-67, 2019.

[9] T. Gao. "Righting treatment of transmission line tower tilt," Rural Electrification, vol. 3, pp. 32-34, 2014.

[10] X.B. Chen, K.X. Gan, P. Cui. "Analysis of the influencing factors of lifting efficiency of prefabricated concrete components based on DEMATEL method," Journal of Engineering Management, vol. 33, no. 6, pp. 111-115, 2019. 
CONVERTER MAGAZINE

Volume 2021, No. 4

[11] J.X. Xu. "Transmission line patrol risks and solutions," Low Carbon World, vol. 13, pp. 32, 2016. 